\title{
Plasma oestrogens in men with chronic liver disease
}

\author{
J. R. B. GREEN, N. A. G. MOWAT ${ }^{1}$, R. A. FISHER ${ }^{2}$, AND D. C. ANDERSON ${ }^{3}$ \\ From the Departments of Gastroenterology, Medicine and Chemical Pathology, St. Bartholomew's Hospital, \\ London
}

SUMMARY A highly specific radioimmunoassay was used to measure the total plasma concentrations of the three principal unconjugated oestrogens: oestrone $E_{1}$, oestradiol $E_{2}$, and oestriol $E_{3}$ in normal males and in 21 males with various forms of chronic liver disease. In addition, the unbound concentration of plasma $\mathrm{E}_{2}$ was established in the same group. About half of the patients with liver disease had overt feminising changes. Total and unbound plasma $\mathrm{E}_{2}$ concentrations were within the normal range in all patients. Total plasma $E_{1}$ was significantly elevated only in those patients with liver disease and gynaecomastia, and a similar trend was seen for total plasma $\mathrm{E}_{\mathbf{3}}$.

Feminisation of some males with chronic liver disease has long been recognized (Corda, 1925). Disturbed metabolism of oestrogens has been postulated as the cause of these changes (Glass et al., 1940; Engel, 1944; Rakoff et al., 1944; Schiller and Pincus, 1944; Gilder and Hoagland, 1946). Measurements of unconjugated plasma oestrogens in these patients have been largely confined to oestradiol $\left(E_{2}\right)$ but results have been conflicting (Korenman et al., 1969; Cedard et al., 1970; Chopra et al., 1973; Galvao-Teles et al., 1973; Kent et al., 1973; Lourens, 1973; Adlercreutz, 1974; Van Thiel, et al., 1974).

An extension of the study to include the other two major oestrogens, oestrone $\left(E_{1}\right)$ and oestriol $\left(E_{3}\right)$, appeared logical in this complex situation. We have therefore studied, for the first time, the basal total plasma concentrations of unconjugated $E_{1}, E_{2}$, and $\mathrm{E}_{3}$ in the same plasma sample; in addition, we estimated the unbound concentration of $E_{2}$. Observations were made in 21 patients with various types of chronic liver disease and in a group of normal controls.

\section{Methods}

\section{PATIENTS}

Twenty-one male patients (mean age 46.9 years, range 27-59 years) were studied. Three had haemochromatosis, five had alcoholic fatty livers, nine had alcoholic cirrhosis, and four non-alcoholic cirrhosis.

'Present address : Department of Gastroenterology, Woodend General Hospital, Woodend, Aberdeen AB9 2YS.

'Pathology Department, Royal Treliske Hospital, Truro, Cornwall.

${ }^{3}$ Medical Unit, Manchester Royal Infirmary.

Received for publication 26 February 1976
One patient in each of the first two groups had gynaecomastia defined as palpable glandular tissue of $>1$ $\mathrm{cm}$ in diameter; seven of the nine with alcoholic cirrhosis had gynaecomastia as did three of the four with non-alcoholic cirrhosis.

Diagnosis was established on the basis of liver biopsy in 20 patients. In the remaining patient, whose clotting defects prohibited liver biopsy, diagnosis was based on clinical history, physical findings, and laboratory tests (including radiology).

Venous blood was withdrawn into heparinised tubes between 9 and 10 am and plasma was immediately separated and stored at $-20^{\circ} \mathrm{C}$ until assayed.

\section{ASSAYS}

Plasma samples $(2 \mathrm{ml})$ were thawed, equilibrated with an internal standard for procedural losses, and extracted twice with five volumes of diethyl ether. The extract was then subjected to Abraham's system of Celite column chromatography (Abraham et al., 1970) by discontinuous solvent elution using increasing concentrations of ethyl acetate in isooctane. This yielded three separate fractions for each sample. Fractions thus obtained were resuspended in phosphate buffer and subjected to radioimmunoassay. Antibody raised to a conjugate of the 6-keto derivative of the parent steroid was used in each case. Cross-reactivity studies showed no steroid tested had a higher cross-reactivity than $5 \%$ (except the 6-keto derivative). Interassay variation was within $15 \%$ for all three assays.

Unbound (free) plasma $E_{2}$ was estimated by multiplication of total plasma $E_{2}$ (estimated as above) by its unbound fraction as determined by steady-state gel filtration (Anderson et al., 1972; Fisher et al., 1974). This method maintains physio- 
logical conditions of temperature and $\mathrm{pH}$ and is performed on undiluted plasma.

\section{Results}

Basal total plasma $E_{1}$ concentrations are shown in Fig. 1. The normal controls had a mean plasma $E_{1}$ of $66.4 \pm 3.8 \mathrm{pg} / \mathrm{ml}$ (mean \pm 1 SEM). Patients with chronic liver disease were divided into two groups on the basis of the presence or absence of gynaecomastia. Those without gynaecomastia had a mean plasma $E_{1}$ of $69.8 \pm 3.5 \mathrm{pg} / \mathrm{ml}$, which was not significantly different from normal Those with gynaecomastia had a mean plasma $E_{1}$ of $117 \cdot 7 \pm 13.4$ $\mathrm{pg} / \mathrm{ml}$, which is both significantly higher than normal controls $(\mathrm{P}<0.005)^{1}$ and patients without gynaecomastia $(P<0.05)^{1}$ Observations on patients with

'Median test and Mann Whitney $u$ statistic.

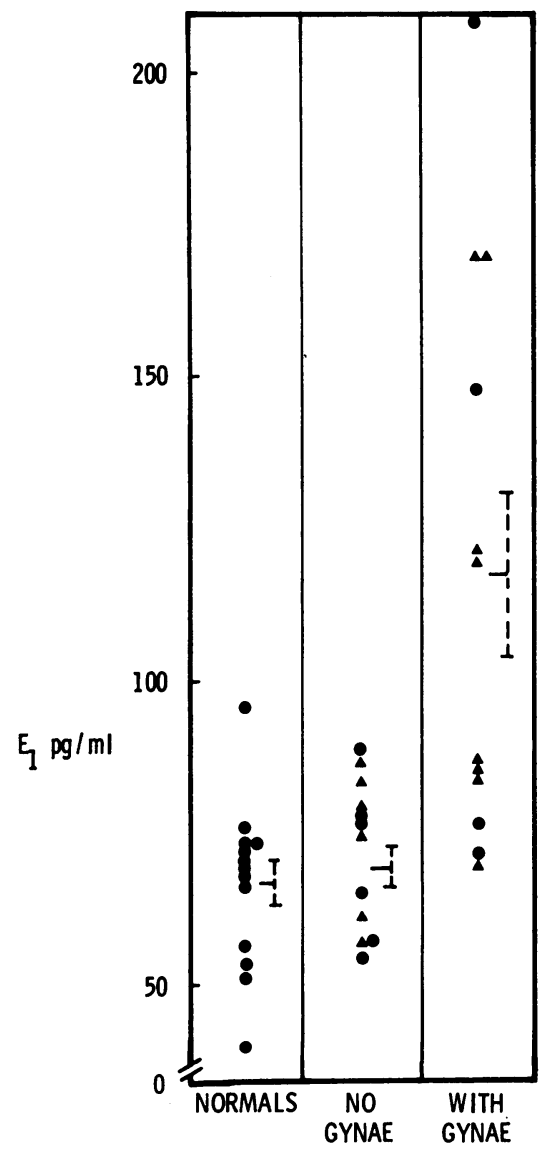

Fig. 1 Basal total plasma oestrone $\left(E_{1}\right)$ concentrations in normal men and in liver disease patients with and without gynaecomastia. Brace: mean \pm 1 SEM. $\bigcirc=$ non-alcoholic aetiology. $\mathbf{\Delta}=$ alcoholic aetiology. alcoholic liver disease appeared evenly scattered throughout both groups.

Total basal plasma oestradiol $\left(\mathrm{E}_{2}\right)$ concentrations are shown in Fig. 2. The mean total plasma $E_{2}$ for normal controls was $29.7 \pm 2.3 \mathrm{pg} / \mathrm{ml}$. Patients with liver disease were divided as before and those without gynaecomastia had a mean total plasma $E_{2}$ of $30.3 \pm 2.8 \mathrm{pg} / \mathrm{ml}$, while the mean value for patients with gynaecomastia was $33.5 \pm 3.9$. There was no significant difference between these groups and normal controls and again observations on those patients with cirrhosis of an alcoholic aetiology were evenly scattered throughout both groups.

Unbound plasma $E_{2}$ concentrations are shown in Fig. 3. All observations except one fall within the normal range, and there are no significant differences between patients with or without gynaecomastia. Observations on patients with alcoholic liver disease were once again evenly distributed throughout both groups.

Total plasma oestriol $\left(\mathrm{E}_{3}\right)$ concentrations are shown in Fig. 4. The mean plasma $\mathrm{E}_{3}$ of patients with gynaecomastia $(50 \cdot 2 \pm 5 \cdot 2 \mathrm{pg} / \mathrm{ml})$ was sig-

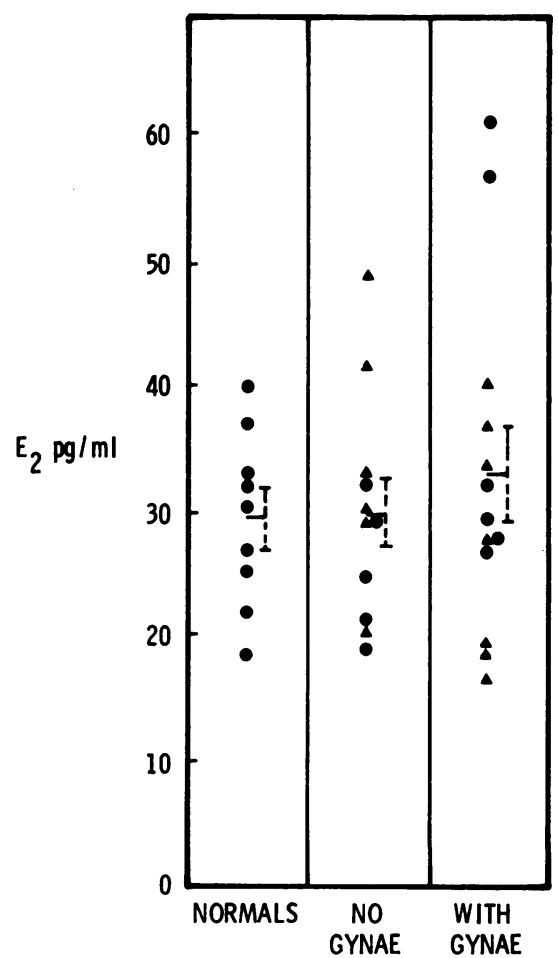

Fig. 2 Basal total plasma oestradiol $\left(E_{2}\right)$ concentrations in normal men and in liver disease patients with and without gynaecomastia. (Key as in Fig. 1). 


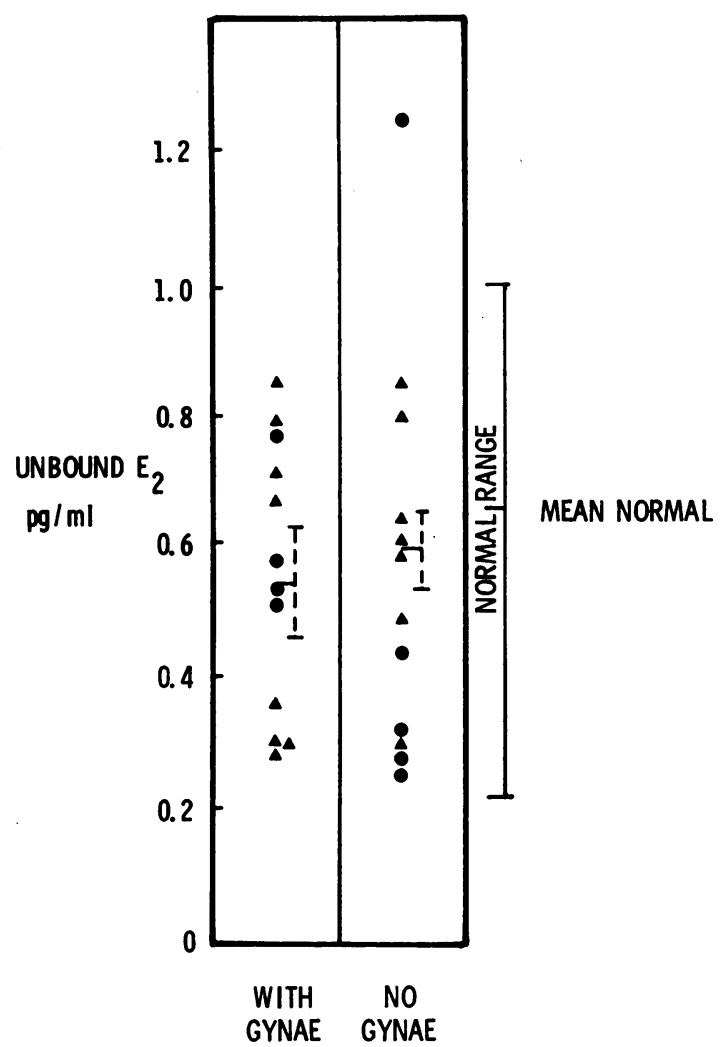

Fig. 3 Unbound (free) plasma oestradiol $\left(E_{2}\right)$ concentrations in liver disease patients with and without gynaecomastia compared with the normal range. (Key as in Fig. 1).

nificantly elevated $(P<0.05)$ above normal controls $(36.8 \pm 3.6 \mathrm{pg} / \mathrm{ml})$, while patients without gynaecomastia (mean $41.9 \pm 3.96 \mathrm{pg} / \mathrm{ml}$ ) appeared to form an intermediate group which was not significantly different from either normal controls or patients with gynaecomastia.

\section{Discussion}

The occurrence of testicuıar atrophy and gynaecomastia in some males with chronic liver disease has long been recognized, but the endocrine basis of such changes remains to be established. The conventional hypothesis, first proposed by Glass et al. (Glass et al., 1940 ) is that the damaged liver fails to inactivate the endogenous oestrogens which are known in normal males to derive both from peripheral conversion of androgens to oestrogens (Longcope et al., 1969) and also from direct testicular secretion (Kelch et al., 1972). The hyperoestrogenic state thus induced in

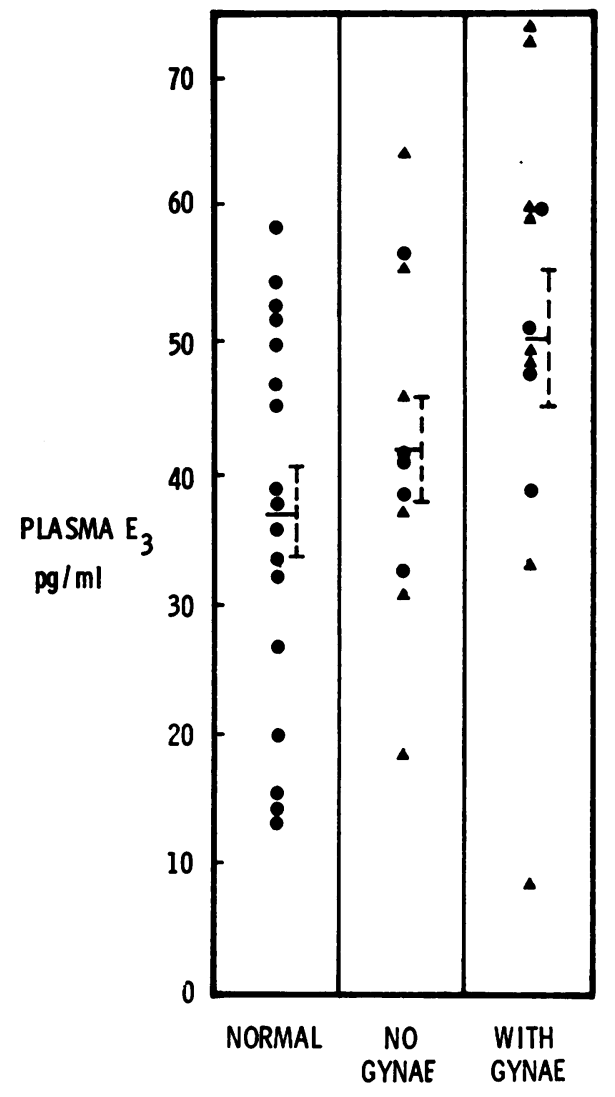

Fig. 4 Basal total plasma oestriol $\left(E_{3}\right)$ concentrations in normal men and in liver disease patients with and without gynaecomastia. (Key as in Fig. 1).

cirrhotic males would then explain both the hypogonadism (by direct suppression of pituitary gonadotrophins) and also the feminisation.

Many studies have recently confirmed the hypogonadism by demonstrating reduced circulating unbound plasma testosterone concentrations and oligospermia or azoospermia in cirrhotic males (Chopra et al., 1973; Galvao-Teles et al., 1973; Mowat et al., 1976), but studies on oestrogens and their metabolites are less conclusive (Adlercreutz, 1974). The early finding of increased urinary oestrogens during the course of acute liver disease using biological assay methods (Gilder and Hoagland, 1946; Llamosa and Gomez Mont, 1953) was not confirmed when biochemical methods of measurement were used (Gregoris, 1957; Müller, 1958). More recently, the measurement of plasma oestrogens (by competitive-binding or immunoassay) has been applied. These studies have been largely confined to the most potent oestrogen, oestradiol $\left(E_{2}\right)$, 
but results have also been conflicting (Korenman et al., 1969; Cedard et al., 1970; Chopra et al., 1973; Galvao-Teles et al., 1973; Kent et al., 1973; Lourens, 1973; van Thiel et al., 1974) with the majority of studies reporting normal total plasma $\mathrm{E}_{2}$ concentrations in cirrhotic males.

In this complex situation, it seemed possible that there might be deranged metabolism of oestrogen metabolites other than $E_{2}$ in cirrhotic males which might contribute to the observed endocrine changes. This study was therefore designed to measure the three principal unconjugated oestrogens normally present in male plasma, oestrone $\left(E_{1}\right)$, oestradiol $\left(E_{2}\right)$, and oestriol $\left(E_{3}\right) . E_{1}$ is the immediate precursor of $E_{2}$, while $E_{3}$ is the major degradation product of the oestrogens in normal males, being excreted mostly as the glucuronide or sulphate conjugate.

The basal total and unbound plasma $\mathrm{E}_{2}$ concentrations in our 21 patients with liver disease of varying aetiologies do not differ significantly from our normal range, regardless of the presence or absence of gynaecomastia. This is in agreement with a previous collaborative study of ours (Galvao-Teles et al., 1973) in which $\mathrm{E}_{2}$ concentrations were measured by protein-binding rather than radioimmunoassay. It is of interest that unbound $E_{2}$ concentrations are normal despite marked changes in steroid binding proteins associated with chronic liver disease.

Our new data concern the other two main oestrogens, $E_{1}$ and $E_{3}$. There are two recent reports of plasma $E_{1}$ concentrations in patients with liver disease. Kley et al. (1975) found that plasma $E_{1}$ was significantly raised in patients with liver disease regardless of aetiology or the presence or absence of gynaecomastia. Van Thiel et al. (1975) report a similar rise but in their patients, all of whom had alcoholic liver disease, those with gynaecomastia had significantly higher plasma $E_{1}$ than those without gynaecomastia. Our findings confirm that there is a significant rise of plasma $E_{1}$ concentrations in patients with gynaecomastia when compared with normal males and with patients with no gynaecomastia. This is true irrespective of the aetiology of the liver disease. Although plasma $E_{1}$ tends to rise with age after 60 years (Kley et al., 1974), all our patients were younger than this, making it unlikely that this factor contributed significantly to the increase. Furthermore, there was no significant age difference between the patients with or without gynaecomastia.

The elevated plasma $E_{1}$ concentration must be due either to increased formation of $E_{1}$ or to a decreased elimination or both. Thijssen et al. (1971) in a preliminary report, found elevated plasma androstenedione in men with cirrhosis of the liver. This could be a source for elevated plasma $E_{1}$.
Impaired elimination of $E_{1}$ is also a possibility, although the tracer studies of Zumoff et al. (1968) have shown that conversion of $E_{1}$ to $16 \alpha$-hydroxyoestrone (the first step in the major degradative pathway) is not impaired in cirrhotic patients. The contribution of elevated plasma $E_{1}$ to feminisation is difficult to assess. A direct feminising action seems unlikely as $E_{1}$ is a biologically weak oestrogen (Vermeulen and Verdonck, 1968). An indirect action-for instance, at hypothalamic-pituitary level- is another possibility. Pituitary function tests performed in these patients have suggested that, in feminised patients only, there may be a circulating inhibitor of gonadotrophin releasing hormone (Mowat et al., 1976). It might be that $\mathrm{E}_{1}$ acts in this way.

We have also found elevated plasma $E_{3}$ concentrations in patients with gynaecomastia. The only other recent study on this plasma steroid in liver disease (Pentikäinen et al., 1975) reports that plasma $\mathrm{E}_{3}$ was raised in men with liver disease, but found no correlation with gynaecomastia in this exclusively alcoholic series. Conversion of $E_{1}$ to $E_{3}$ via 16 $\alpha$-hydroxyoestrone is known to be relatively impaired in patients with cholestasis but whose liver function is otherwise normal (Adlercreutz et al., 1974). This effect is attributed to the interruption of the enterohepatic circulation in cholestasis, since Breuer and Breuer (1973) showed in vitro that the ability of liver microsomes to metabolise $E_{1}$ to $E_{3}$ was not impaired in cirrhotic livers. Impaired conjugation of $E_{3}$ is an unlikely explanation for our findings, as oestrogen conjugation has been shown to remain unimpaired even in advanced hepatic failure (Adlercreutz and Tenhunen, 1970). It may be that our finding of elevated levels merely reflects a normal rate of degradation of the elevated $E_{1}$. It is uncertain how much oestrogenic activity $E_{3}$ has, and its importance in causing feminisation is uncertain.

In conclusion, we have found raised plasma $E_{1}$ and $E_{3}$ concentrations in association with normal total and unbound plasma $\mathrm{E}_{2}$ concentrations in the men with liver disease and gynaecomastia, and this suggests that the increase of one or both of these oestrogens may be of aetiological importance in causing feminisation in these patients. There is no association between these abnormalities of oestrogen metabolism with any aetiological factor, notably alcohol.

We are grateful to the Wellcome Research Foundation and the North East Thames Area Health Authority for financial support. We are also grateful to Professor J. Landon for the use of his laboratory and to Miss Monica Leighton for help with the statistical analyses of results. We are also gratefu 
to the following for their provision of the antibodies for the assays: $\mathrm{Dr} \mathrm{A}$. Boulton for $\mathrm{E}_{1}$ antiserum, $\mathrm{Dr}$ B. Furr for the $E_{2}$ antiserum, and Miss Shahla Khoshroo for the $E_{3}$ antiserum.

\section{References}

Abraham, G. E., Tulchinsky, D., and Korenman, S. G.(1970). Chromatographic purification of estradiol-17 $\beta$ for use in radio-ligand assay. Biochemical Medicine, 3, 365-368.

Adlercreutz, H. (1974). Hepatic metabolism of estrogens in health and disease. New England Journal of Medicine, 290, 1081-1083.

Adlercreutz, H., and Tenhunen, R. (1970). Some aspects of the interaction between natural and synthetic female sex hormones and the liver. American Journal of Medicine, 49, 630-648.

Adlercreutz, H., Tikkanen, M. J., Wichmann, K., Svanborg, A., and Anberg, A. (1974). Recurrent jaundice in pregnancy. IV. Quantitative determination of urinary and biliary estrogens, including studies in pruritus gravidarum. Journal of Clinical Endocrinology and Metabolism, 38, 51-57.

Anderson, D. C., Marshall, J. C., Galvao-Teles, A., and Corker, C. S. (1972). Gynaecomastia and impotence associated with abnormal testosterone binding. Proceedings of the Royal Society of Medicine, 65, 787-788.

Breuer, J., and Breuer, H. (1973). Halbwertszeit von $\left(4-{ }^{14} \mathrm{C}\right)$ Ostradiol-17 $\beta$ in vivo sowie Stoffwechsel von $\left(4-{ }^{14} \mathrm{C}\right)$ Östron und $\left(4-{ }^{14} \mathrm{C}\right)$ Ostriol in vitro lei Lebergesunden und bei Patienten mit Lebercirrhose. Zeitschfrit klinische für Chemie und klinische Biochemie, 11, 263-269.

Cedard, L., Mosse, A., and Klotz, H. P. (1970) Les oestrogènes plasmatiques dans les gynécomasties et les hépatopathies. Annales d'Endocrinologie, 31, 453-458.

Corda, L. (1925). Scilla c.d. reviviscenza della mammella maschile nella cirrosi epatica. Minerva Medica (Torino), 5 , 1067-1069.

Chopra, I. J., Tulchinsky, D., and Greenaway, F. L. (1973). Estrogen-androgen imbalance in hepatic cirrhosis. Annals of Internal Medicine, 79, 198-203.

Engel, P. (1944). A study on inactivation of ovarian hormones by the liver. Endocrinology, 35, 70-72.

Fisher, R. A., Anderson, D. C., and Burke, C. W. (1974). Simultaneous measurement of unbound testosterone and estradiol in undiluted plasma at $37^{\circ} \mathrm{C}$ by steady-state gel filtration. Steroids, 24, 809-823.

Galvao-Teles, A., Anderson, D. C., Burke, C. W., Marshall, J. C., Corker, C. S., Bown, R. L., and Clark, M. L. (1973) Biologically active androgens and oestradiol in men with chronic liver disease. Lancet, 1, 173-177.

Gilder, H., and Hoagland, C. L. (1946). Urinary excretion of estrogens and 17-ketosteroids in young adult males with infectious hepatitis. Proceedings of the Society for Experimental Biology and Medicine, 61, 62-65.

Glass, S. J., Edmondson, H. A., and Soll, S. N. (1940). Sex hormone changes associated with liver disease. Endocrinology, 27, 749-752.

Gregoris, L. (1957). Il turbato metabolismo degli estrogeni nella malattie del fegato, con riferimento al determinismo della ginecomastia. Acta Medica Patavina, 17, 277-294.

Kelch, R. P., Jenner, M. R., Weinstein, R., Kaplan, S. L., and Grumbach, M. M. (1972). Estradiol and testosterone secretion by human, simian and canine testes, in males with hypogonadism and in male pseudo hermaphrodites with the feminizing testes syndrome. Journal of Clinical Investigation, 51, 824-830.

Kent, J. R., Scarramuzzi, R. J., Lauwers, W., Parlow, A. F., Hill, M., Penardi, R., and Hilliard, J. (1973). Plasma testosterone, oestradiol and gonadotrophins in hepatic insufficiency. Gastroenerology, 64, 111-115.

Kley, H. K., Nieschlag, E., Bidlingmaier, F., and Krüskemper, H. L. (1974). Possible age-dependent influence of estrogens on the binding of testosterone in plasma of adult men. Hormone and Metabolism Research, 6, 213-216.

Kley, H. K., Nieschlag, E., Wiegelmann, W., Solbach, H. G. and Krüskemper, H. L. (1975). Steroid hormones and their binding in plasma of male patients with fatty liver, chronic hepatitis and liver cirrhosis. Acta Endocrinologica (Kbh.), 79, 275-285.

Korenman, S. G., Perrin, L. E., and McCallum, T. (1969). Estradiol in human plasma; demonstration of elevated levels in gynaecomastia and in cirrhosis. Journal of Clinical Investigation, 48, 45a.

Llamosa, J. L., and Gomez Mont, F. (1953). Alteraciones hormonales en la hepatitis aguda por virus. Revista de Investigacion Clinica (Mexico), 5, 9-25.

Longcope, C., Kato, T., and Horton, R. (1969). Conversion of blood androgens to estrogens in normal adult men and women. Journal of Clinical Investigation, 48, 2191-2201.

Lourens, J. (1973). Gestachtshormonen en Lebercirrhose, p. 125. Thesis: University of Utrecht.

Mowat, N. A. G., Edwards, C. R. W., Fisher, R., McNeilly, A. S., Green, J. R. B., and Dawson, A. M. (1976). Hypothalamic-pituitary-gonadal dysfunction in men with cirrhosis of the liver Gut. 17, 345-350.

Müller, J. (1958). Über die Phenolsteroidausscherdung bei der Lebercirrhose des Mannes. Acta Endocrinologica (Kbh.), 28, 205-212.

Pentikäinen, P. J., Pentikäinen, L. A., Azarnoff, D. L., and Dujovne, C. A. (1975). Plasma levels and excretion of estrogens in urine in chronic liver disease. Gastroenterology, 69, 20-27.

Rakoff, A. E., Cantarow, A. Paschkis, K. E., Hansen, L. P., and Walkling, A. A. (1944). Removal of exogenous estrogens from the circulation. Endocrinology, 34, 370-375.

Schiller, J., and Pincus, G. (1944). The metabolism of estrone in normal and partially hepatectomized rats. Endocrinology, 34, 203-209.

Thijssen, J. H. H., Lourens, J., and Donker, G. H. (1971). Androstenedione and testosterone production and interconversion rates measured in peripheral blood in male patients with cirrhosis of the liver. Acta Endocrinologica (Kbh.), suppl., 155, 116.

Van Thiel, D. H., Gavaler, J. S., and Lester, R. (1975). Plasma estrone and prolactin concentrations are elevated in men with gynecomastia and spider angiomata. Gastroenterology, 68, 934.

Van Thiel, D. H., Lester, R., and Sherins, R. J. (1974). Hypogonadism in alcoholic liver disease; evidence for a double defect. Gastroenterology, 67, 1188-1199.

Vermeulen, A., and Verdonck, L. (1968). Studies on the binding of testosterone to human plasma. Steroids, 11, 609-635.

Zumoff, B., Fishman, J., Gallagher, T. F., and Hellman, L. (1968). Estradiol metabolism in cirrhosis. Journal of Clinical Investigation, 47, 20-25. 